\title{
Description of a Triad of Rare Malignancies in a Single Patient
}

\author{
David Fackrell, Yen Yeo, Nawaz Walji \\ University Hospital Coventry, Coventry, UK \\ Email: davidfackrell@nhs.net
}

Received 2 March 2015; accepted 17 March 2015; published 20 March 2015

Copyright (C 2015 by authors and Scientific Research Publishing Inc.

This work is licensed under the Creative Commons Attribution International License (CC BY). http://creativecommons.org/licenses/by/4.0/

c) (7) Open Access

\begin{abstract}
We describe the case of a patient diagnosed with a rhabdomyosarcoma and two distinctly separate non-epithelial ovarian cancers. Granulosa cell tumour and Sertoli-Leydig tumour are rare tumours accounting for less than $10 \%$ of all ovarian malignancies. Rhabdomyosarcoma is also rare and more commonly seen in childhood. We link these tumours to a mutation in the forkhead transcription factor proteins.
\end{abstract}

\section{Keywords}

\section{Granulosa Cell Tumour, Sertoli-Leydig Tumour, Rhabdomyosarcoma, Forkhead Transcription} Factor Proteins

\section{Introduction}

Non-epithelial ovarian cancers (NEOC) account for less than $10 \%$ of all ovarian malignancies; the aetiology of these rare tumours remains largely unknown. Rhabdomyosarcoma is a rare form of sarcoma more commonly diagnosed in childhood and is believed to originate from skeletal muscle. We describe the case of a patient diagnosed with a rhabdomyosarcoma and two distinctly separate NEOC.

\section{Case}

In 1980 a previously well thirteen-year-old girl presented with an eight-week history of intermittent vaginal bleeding and acute right iliac fossa pain. Clinical examination revealed a right sided abdominal mass. Laparotomy and right salpigo-oophrectomy was performed to remove an abnormal looking " $8 \times 6$ " right-sided ovarian mass. The histo-pathology report, reviewed for a second opinion at a reference centre, confirmed a granulosa cell tumour (GCT). No adjuvant treatment was required and the patient remained under clinical surveillance. 
In December 1993 the patient, now pregnant aged 26, presented to the ophthalmology department with an acute severely painful red left eye requiring emergency enucleation. Histo-pathological findings confirmed a primary intra-ocular rhabdomyosarcoma positive for desmin, actin and myoglobin on immunohistochemistry, developing in a teratoid medulloepithelioma. Following safe delivery of her daughter, staging investigations revealed no evidence of metastatic disease. The patient received adjuvant therapy with six cycles of chemotherapy (vincristine, ifosfomide and actinomycin D) followed by radiotherapy to the tumour bed (4500 cGy in 20 fractions).

In 2005 a surveillance pelvic ultrasound scan reported the presence of an asymptomatic left ovarian cystic mass. The patient underwent laparotomy, omentectomy, total abdominal hysterectomy and left salpingo-oophrectomy. Histo-pathology reported an intermediately differentiated Sertoli-Leydig cell tumour, FIGO stage 1. No adjuvant treatment was advocated and the patient remains under clinical surveillance. To date, there is no evidence of recurrence of her three previously treated rare malignancies (Figure 1).

The patient has been genetic counselling which she has declined. There is no known family history of malignancies.

\section{Discussion}

The forkhead box (FOX) family of transcription factors are named after the ectopic head structures observed in mutants of the Drosophila gene $F k h$, which became the family's founding member and were first described by Weigel and colleagues 25 years ago [1]. Forkhead factors influence a wide range of biological processes including development of cell types from all three germ layers, cell cycle control and cellular survival. Expression of several $F k h$ genes has been correlated with different cancers [2] [3].

A single point mis-sense mutation (C134W) was found in the FOXL2 gene in approximately $95 \%$ of adulttype GCT, suggesting a key role for FOXL2 in these tumours [4]. Shah and colleagues have postulated that a single mis-sense mutation in FOXL2 (C $\rightarrow \mathrm{G})$ may be responsible for development of GCT. They reported 86 of 89 morphologically identified GCT had this mutation and have suggested testing for this mutation may improve diagnostic and therapeutic options [5]. In 2011 a Canadian group published a cost effective method for staining FOXL2 and reported $50 \%$ of Sertoli-Leydig tumours tested also had a mutation in the gene [6].

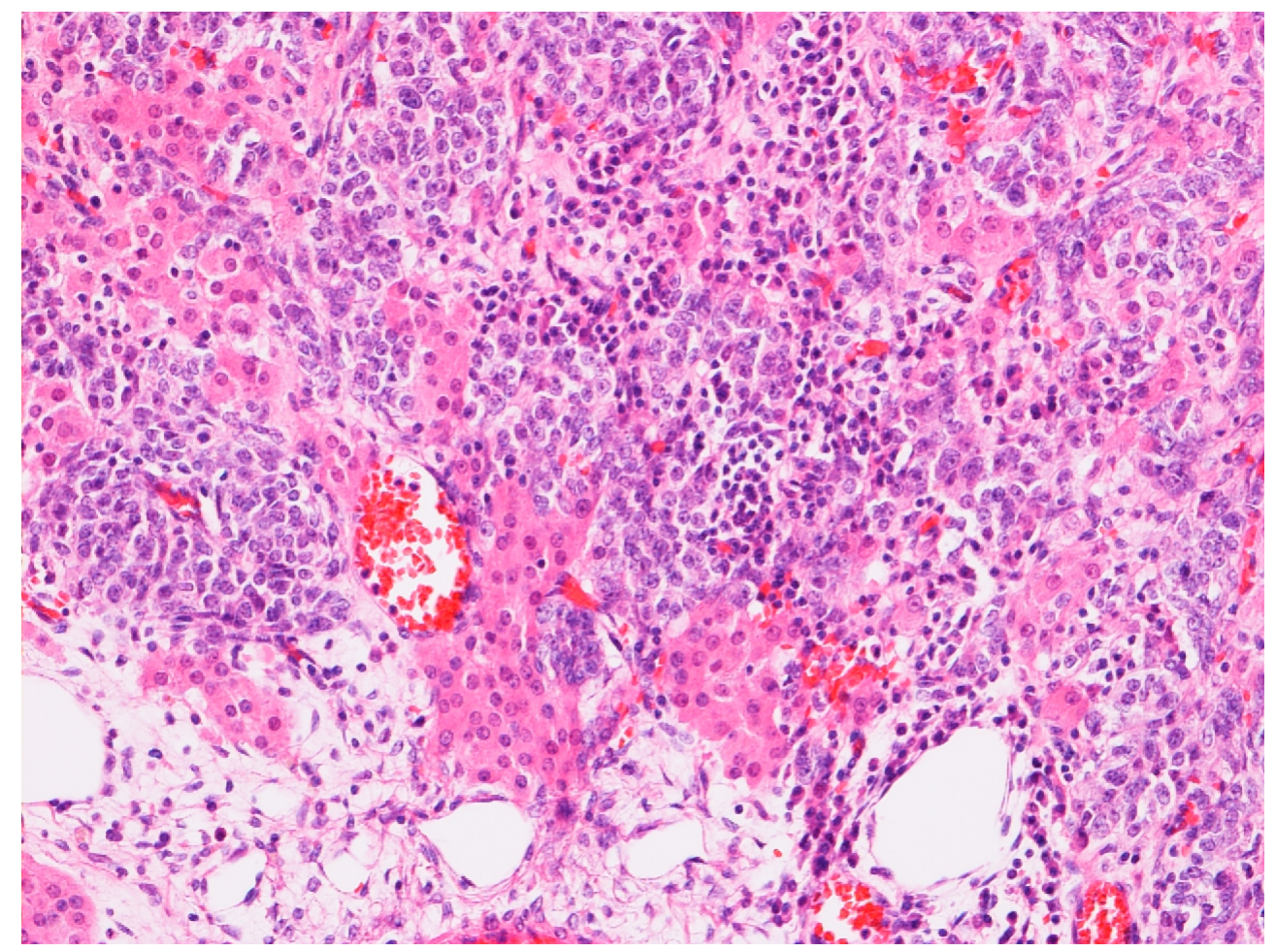

Figure 1. Patients Sertoli-Leydig tumour. 
The majority of alveolar rhabdomyosarcoma are characterised by a PAX3-FOXO fusion oncoprotein generated by a $2 ; 13$ chromosomal translocation [7]. It is believed that different stages of folliculogenesis, both in oocytes and in somatic granulosa and theca cells, are regulated by FOXC1, FOXL2, and FOXO subfamily members [8]. A report by Missiaglia et al. [9] included 171 patients with alveloar rhabdomyosarcoma, including patients with non-metastatic disease. They reported that the subset with $P A X 3 / F O X O 1$ mutation had a significantly poorer outcome compared with the $P A X 7 / F O X O 1$ mutation or the fusion-negative group.

It is possible that the FOX family of transcription factors is associated with the three cancers described in this patient However, linking the tumours, in this patient, to the forkhead transcription factor proteins is impossible without any proven molecular aetiology. Our patient has refused genetic testing.

We would suggest however, that $P A X 3 / F O X O 1$ fusion gene status is a key molecular marker and may improve risk stratification and therapy of these rare malignancies

\section{Conclusion}

We describe what we believe to be the first report of a single patient with these rare tumours. It is possible our patient may harbour a mutation in the FOX transcription factor proteins but has declined genetic testing.

\section{Consent}

Formal written consent has been obtained by the patient.

\section{Conflict of Interest}

The authors have no conflicts of interest.

\section{References}

[1] Weigel, D., Jürgens, G., Küttner, F., Seifert, E. and Jäckle, H. (1998) The Homeotic Gene Fork Head Encodes a Nuclear Protein and Is Expressed in the Terminal Regions of the Drosophila Embryo. Cell, 57, 645-658. http://dx.doi.org/10.1016/0092-8674(89)90133-5

[2] Hannenhalli, S. and Kaestner, K.H. (2009) The Evolution of Fox Genes and Their Role in Development and Disease. Nature Reviews Genetics, 10, 233-240. http://dx.doi.org/10.1038/nrg2523

[3] Uhlenhaut, N.H., Jakob, S., Anlag, K., Eisenberger, T., Sekido, R., Kress, J., Treier, A.C., Klugmann, C., Klasen, C., Holter, N.I., Riethmacher, D., Schütz, G., Cooney, A.J., Lovell-Badge, R. and Treier, M. (2009) Somatic Sex Reprogramming of Adult Ovaries to Testes by FOXL2 Ablation. Cell, 139, 1130-1142.

[4] Van Nieuwenhuysen, E., Lambrechts, S., Lambrechts, D., Leunen, K., Amant, F. and Vergote, I. (2013) Genetic Changes in Nonepithelial Ovarian Cancer. Expert Review of Anticancer Therapy, 13, 871-882.

[5] Shah, S.P., et al. (2009) Mutation of FOXL2 in Granulosa-Cell Tumors of the Ovary. The New England Journal of Medicine, 360, 2719-2729. http://dx.doi.org/10.1056/NEJMoa0902542

[6] Al-Agha, O.M., Huwait, H.F., Chow, C., Yang, W., Senz, J., Kalloger, S.E., Huntsman, D.G., Young, R.H. and Gilks, C.B. (2011) FOXL2 Is a Sensitive and Specific Marker for Sex Cord-Stromal Tumors of the Ovary. American Journal of Surgical Pathology, 35, 484-494. http://dx.doi.org/10.1097/PAS.0b013e31820a406c

[7] Ahn, E.H. (2013) Regulation of Target Genes of PAX3-FOXO1 in Alveolar Rhabdomyosarcoma. Anticancer Research, 33, 2029-2035.

[8] Uhlenhaut, N.H. and Treier M. (2011) Forkhead Transcription Factors in Ovarian Function. Reproduction, 142, 489495. http://dx.doi.org/10.1530/REP-11-0092

[9] Missiaglia, E., Williamson, D., Chisholm, J., et al. (2012) PAX3/FOXO1 Fusion Gene Status Is the Key Prognostic Molecular Marker in Rhabdomyosarcoma and Significantly Improves Current Risk Stratification. Journal of Clinical Oncology, 30, 1670-1677. http://dx.doi.org/10.1200/JCO.2011.38.5591 